\title{
Towards Social Entrepreneurship and Sustainable Development in Lebanon
}

\author{
Malak Bou Diab \\ The Bucharest University Of Economic Studies, Bucharest, Romania \\ Lebanese International University, Beirut, Lebanon \\ Malakboudiab@Outlook.Com
}

\begin{abstract}
Faced with provocation emerged from sustainable development, several states, and in specific organizations and other related social performers, are asking their tasks and desire to take dynamic perspective to social accountability. In doing this, they are faced with sustainable development challenges. Entrepreneurship constitutes the business efforts of an individual or group for earning profit and ensuring economic empowerment, while social entrepreneurship involves the business activities with an embedded social purpose focused on sustainability rather than immediate outcomes. Entrepreneurship is an important factor of economy. The development of social entrepreneurship needs a structural adjustment in the society. The principal paper aim is to investigate the social entrepreneurship role in improving sustainable development. Also, the paper will examine social entrepreneurship as an effective tool in resolving social problems, noting that social entrepreneurship analysis can provide a response to sustainable development challenges. The research focuses on addressing the current state of social entrepreneurship, entrepreneurship indicators, pillars of entrepreneurship development, business environment and entrepreneurial opportunity and signifying the practicality of dissimilar business models developed in social entrepreneurship. Surveys were conducted on fifty different organizations (banks and audit companies) to collect data. Also, SPSS system was used to analyze the data gathered, to study the relationship between sustainable development and social entrepreneurship. Evidence suggests that social entrepreneurship can play a significant role for poverty reduction, ensuring employment, economic prosperity, environmental justice, pollution free ecology, good governance, reduction of terrorism, guarantee of peace, corruption control etc., thus offering opportunities to fulfill sustainable development goals in Lebanon. We can conclude that social business models develop a basic spread that grant social entrepreneurs to participate actively to sustainable development.
\end{abstract}

Keywords: Entrepreneurship, Sustainability, Development, Social, Ecology, Green Society.

\section{Introduction}

Today, many problems surround communities that are linked to Community Development. Social entrepreneurship is booming in poor communities as a pioneer in dealing with these problems. Whether individuals or social entrepreneurs are recognized as a powerful agent of change for community's development, it is important to understand from the communities how the development of the community is affected by social entrepreneurship and to determine the importance of its impact on a long- term basis. The significance is that stakeholders must be aware of Social Entrepreneurship influence in order to appreciate the value of the input made by Social Entrepreneurs.

Social entrepreneurs see opportunities and potential for investing in the development of communities. When organizations and governments fail to provide basic services to communities, social entrepreneurship has come to life to address these issues that go beyond the socio - economic sectors of health, education, housing, climate change and clean water. 
Lebanon is faced with a number of socio - economic problems, such as education, health and housing, which Social Entrepreneurs see as opportunities to encourage change. From the vibrant potential that Social Entrepreneurship offers for social enterprise activities to proliferate in the country, it is necessary to develop programs with clear objectives, to ensure that they are measurable and to evaluate sufficient results. However, measuring the impact of Social Entrepreneurship activities at first sight is challenging because the impact takes some time to be visible.

The paper will examine social entrepreneurship as an effective tool in resolving social problems, noting that social entrepreneurship analysis can provide a response to sustainable development challenges.

However, recent studies provide a strong case studying social entrepreneurship because of its role in maintaining sustainable development, for instance, Emerson and Twersky (1996) in their study revealed that social entrepreneurship is the key to nonprofit creations. Also, Bhatt (1989) corroborating Emerson and Twersky (1996) in his study, found that social enterprise is a potential way to empower people, develop rural women and solve other social problems.

\section{Literature review}

Lebanon is a country characterized by an upper middle income and a democratic political system. It has an entrepreneurial liberal economy and a society characterized by cultural diversity and openness, which is mainly based on services. Located in the center of one of the world's most volatile regions, Lebanon has been exposed, since the late 1990s, to lack of security, political and economic shocks. Yet, many storms have been successful in shaking the prevailing political regime and namely the 2005 assassination of late Prime Minister H.E. Rafiq Hariri, the 2006 Israeli invasion, and the repercussions of the prolonged Syrian crisis.

Since the beginning of the conflict in Syria in 2011, domestic political tensions have aggravated the regional geo- political instability, which imposed a major impact on the Lebanese economy. By the end of 2016, Lebanon embarked on a positive and stable path after the "national unity" government was formed, and a new President of the Republic was elected. A National Committee was formed, chaired by the Prime Minister, to oversee the rollout of the Sustainable development goals. In addition to representatives from all the ministries, the National Committee includes representatives from the civil community in order to generate broad ownership of the agenda.

Much of the theoretical work on entrepreneurial literature in this part of the world has focused on business and small enterprises in particular. The lack of integration in strategies, policies and implementation across sectors has long been seen as one of the main obstacles to previous sustainable development approaches.

To face the challenges of sustainable development, several nations, organizations and other social performer question their performance and want to adopt proactive path to social responsibility. In order to meet its commitment to the sustainable development Goals, the Lebanese Government developed a strong institutional mechanism to ensure that relevant stakeholders are widely involved. A proper understanding of how specific aspects such as social entrepreneurship shape the development will obviously allow stakeholders to anticipate the impact better.

Government commitments to these specifics culminate in sustainable development, as all the infrastructures required for broad development are included. It's using an inclusive, 
Government - wide approach, involving civil society and the business sector. At the same time, the Government's commitment to Agenda 2030 has accelerated and incorporated a commitment from the international community.

Entrepreneurship is a function performed by an entrepreneur which gives birth to a new enterprise. It is also an attempt to create value by recognizing business opportunities, managing risk - taking and managing skills to line up the human, financial and material resources required to realize the desired results (Kao and Stevenson, 1984). After the crisis hitting the global economy in the early1990's, Entrepreneurship became a subject of considerable importance in academic literature.

Social entrepreneurship is a new breed of entrepreneurs though it has its root in entrepreneurship because of the attributes of innovativeness, creative critical thinking and motivation. When these attributes are combined with the drive to solve social problems, social entrepreneurship takes place. This specific characteristic of entrepreneurship is not popular in Lebanon as is the case in more developed countries.

The growth of entrepreneurship reflects rise in social, cultural and business pressure. The resulting, is a social variable that has been viewed as a factor requiring adequate attention in entrepreneurship (Stevenson and Jarillo, 2007).

The common factor found in social entrepreneurs is their focus on making change through their actions, which may lead to solutions to society problems.

Social entrepreneurs are individuals with new concept to tackle main issues that are determined in the pursuance of their perceptions, people who simply will not terminate until their ideas are spread to the extent they can (Bornstein, 2007).

\section{Social Entrepreneurs' Characteristics}

The following key attributes characterize social entrepreneurs (Martin and Osberg, 2007):

\begin{tabular}{|l|l|}
\hline Attributes & Meaning \\
\hline Ambitious & $\begin{array}{l}\text { Social entrepreneurs have a high initiative and are reformers with a social aim, tackling major } \\
\text { social obstacle and offering raw concepts and wide - ranging clarifications. }\end{array}$ \\
\hline Strategic: & $\begin{array}{l}\text { Searching and identifying what other social issues are missing, they take advantage of these } \\
\text { opportunities for improving current social systems, creating solutions and inventing new } \\
\text { methods that create satisfactory social values. }\end{array}$ \\
\hline Resourceful: & $\begin{array}{l}\text { Social entrepreneurs do not function in the business world in a social framework. As a result } \\
\text { of their limited access to capital requirements, they have skills and mobilize all necessary } \\
\text { resources for solving social problems. }\end{array}$ \\
\hline Mission: & $\begin{array}{l}\text { Successful social entrepreneurs have the extreme goal not only of building wealth, but also } \\
\text { of developing as much social value as possible. }\end{array}$ \\
\hline Result: & $\begin{array}{l}\text { Social entrepreneurs are ultimately driven to achieve significant outcomes that adjust } \\
\text { current situations for the benefit of society as a whole. }\end{array}$ \\
\hline
\end{tabular}

Social entrepreneurship, which promotes sustainable development that respects human rights and takes care of a reasonable use of resources, refers to the treatment of complex social and wicked problems such as unemployment, crime, drug addiction problems, poverty and social exclusion. (Johnson, 2000).

Social entrepreneurship provides new clarification to prompt social problems and organizes the concepts capacities, funds and social arrangements necessary to make social transformations sustainable (Alvord, Brown et al., 2004).

According to Martin and Osberg (2007), Three basic components of social entrepreneurship are: Identifying a stable but unjust balance that prevent, criticizes or 
damage a group that does not have the instrument to improve balance; recognizing opportunity chance and expanding a newly proposed social value to claim balance; and finally, the suffering by creating a durable ecosystem was alleviated by the development of a new stable balance to provide a better future.

Finally, Zahra et al's contribution (2009) which adds and synthesizes a literature review on social entrepreneurship and includes the scheme and processes to increase social wealth by innovatively establishing new enterprises or managing current organizations.

Now we will talk about the importance of sustainable development; is a model for the resources use that aim to achieve the human requirement while protecting the environment, so that these needs can be achieved in the future.

The concept of sustainable development is increasingly acknowledged. In order to achieve its potential for sustainable development, it must be integrated into enterprise planning and measuring systems. Therefore social entrepreneurship for sustainable development processes social entrepreneurship by achieving the demand of today's generation without negotiating future generations ' capability in meeting their own needs.

After presenting these different definitions and conceptions of social entrepreneurship, we can emphasize that this concept refers to the existence of two basic components: discovering and exploiting business opportunities by reviewing new issues that traditional organizations have not yet explored or completed; creating a social value for the needy.

\section{Lebanon's Sustainable Development Goals}

The Government of Lebanon engages towards Agenda 2030 by United Nations, while adopting a localization approach. Lebanon has developed a strong commitment institutional mechanism ensuring the broad involvement of relevant stakeholders (SDG, 2018).

Sustainable Development Goals Agenda 2030:

Agenda 2030 is a program consisting of people, planet and wealth. It is also intended to construct global peace in greater privilege. The 17 sustainability goals and 169 targets announced show the range and initiative of this new global agenda.

They are integrated with the three dimensions of sustainability: economic, social and environmental development. Over the next 15 years, the targets and goals will push forward actions in fields of crucial significance to human kind and the planet:

People: aims to make sure that all people can reach their potential in a dignified, equitable and healthy environment to end poorness and hunger in all its forms

Planet: aims to secure the planet from humiliation through sustainable utilization and production in order to reasonably guide its natural resources movement in order to encounter the needs of current and future generations.

Prosperity: is to offer prosperous and fulfilling lives for all people, and the harmony with the environment took place with economic, social and technological progress

Peace: is performed to be sure that everyone benefit from a prosperous and fulfilling life and that economic, social and technological advances match with the environment. 
Partnership: is committed to mobilize the necessity of implementing the agenda in accordance with the global partnership for sustainable development by strengthening the global solidarity spirit . It focuses in specific on the needs of the needy and most vulnerable, involving all countries, stakeholders and everyone.

In March 2018, the national committee held its first meeting, led by the Prime Minister and with the participation of the Deputy Prime Minister. During this meeting, the establishment of the 4Ps was done and the fifth P refers to the partnership was considered a cross - cutting issue in the implementation and achievement of the SDGs. A task force for statistics) has been set up to collect data and statistics related to the SDG (Figure 1). (SDG,2018)

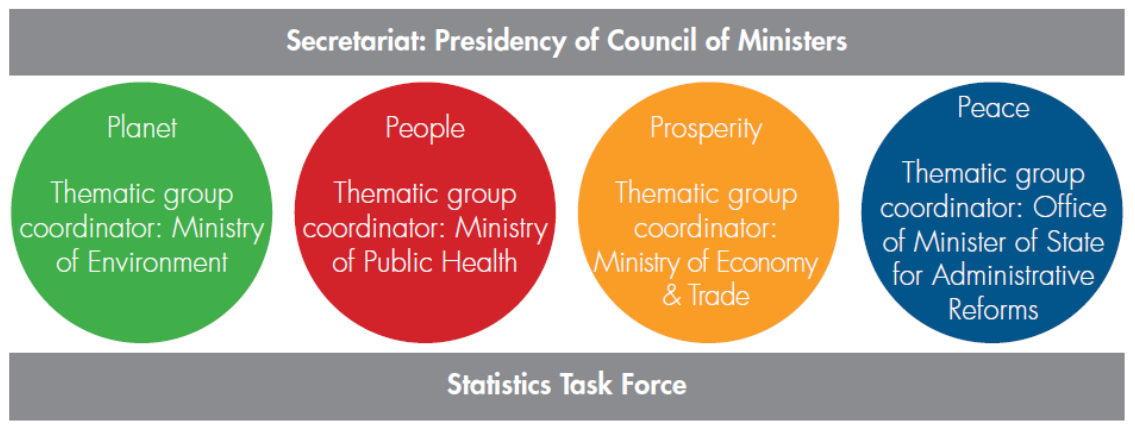

Figure 1: Structure of Lebanon's SDG's National Committee

Source: www.un.org.lb

Therefore social entrepreneurship has been playing a major role in achieving sustainable development.

\section{The Link between Social Entrepreneurship and Sustainable Development}

The UN Country Team facilitates and provides coordination between all UN agencies operating in Lebanon with the main objective of achieving tangible and solid results at national, progressive, humanitarian and political level of the corresponding action plan.

The development program of the United Nations (UNDP) is the universe enlargement network. It promotes positive change and brings countries into contact with knowledge and capital in order to help those building better lives. Since 1960, the UNDP has been supporting the government of Lebanon and the people in recovering from the civil war, building harmony, generating maintainable and reasonable growth. With the rise of the Syrian crisis the UNDP has enlarged its reach in order to help the population in Lebanon to adapt with the effect of the inundation of Syrian refugees.

Also, they arrange the poor for self-support and offer local capacities for economic growth, education and women entrepreneurs. The focus is on enhancing the capabilities of poor and restricted people especially women in the rural areas to participate in small businesses. These initiatives have impacted highly on the social economic and political environment.

Lebanon attained targets related to wellbeing, principal education and education gender equality. However, the most dangerous objectives have not been met such as the reduction of poverty and environmental sustainability.

Among this exposure which is obtainable in developed nations and the Asian countries that are fast growing economies this gap must be filled if sustainable development 
is to be attained through entrepreneurial expressions. The ability to think creatively is an essential skill for every social entrepreneur.

Creativity of social entrepreneur helps to understand the process of originating, assessing and sharing ideas that provide solution. On a social level, collectivity creativity provides the opportunity to improve quality of life of people. This has been supported by empirical studies of some social entrepreneurs who refused to be constrained by culture and circumstance and were tired of doing things the way they were always done. Instead they see problems as opportunities to find new ways of doing things by using creative thinking to gain a new perspective on the world.

The term 'sustainable entrepreneurship' is consisted of two terms sustainability and entrepreneurship. This kind seeks success in order to resolve ecological and societal problems, while the community of green social entrepreneurs has a broader view of sustainable development (Schaltegger and Wagner, 2011)

The relationship between these two terms "entrepreneurship" and "sustainable development" has been marked in different means, such as ecopreneurship, social entrepreneurship, sustainable entrepreneurship and, indirectly, institutional entrepreneurship.

Based on the literature on sustainable development and entrepreneurship, we propose the following definition:

Sustainable entrepreneurship focuses on protecting human nature and the earth that we live in. As well, it is the fact that businesses are accountable to create a better future for societies.

\section{Methodology}

Social entrepreneurship reporting is a means of providing stakeholders with an insight into their contribution to sustainable development in Lebanon, not just focusing on business. Data were gathered by surveying entrepreneurs and institutional employees involved in social activities. Fifty questionnaires were distributed to companies in Lebanon and entrepreneurs as follows:

- 10 Audit Companies

- 30 Banks

- 10 entrepreneurs

By definition, data collection is the process in which primary data are collected from samples through surveys, questionnaires and interviews to be able to answer the research question or problem in order to produce original research results (Bryman \& Bell, 2015).

The sample size for this study was of 50 participants, obtained by using the margin of error formula. The respondents in the companies are from the managerial level and have responsibilities regarding the entrepreneurship. "Questionnaires" have been the easiest and fastest method of data collection. "Quantitative data" was captured in tables and qualitative data was captured using codes and numbers. By using recognized validity and reliability, the researcher made sense of the data to analyze and ensure that the data was confidential. The answers were analyzed and the statistics using Spss system from the data collected from the questionnaires were provided.

The data were obtained via the Linkert scale, ranging from (1) Low to (3) high and a general hypothesis with sub hypothesis was formulated to evaluate the extent of the relationship between social entrepreneurship and sustainable development in Lebanon and whether social entrepreneurship is an effective tool to solve social problems. 
Data processing was carried out using a simple statistical co-relation tool. All analyzes were carried out using 95 percent confidence.

\section{Results and discussions}

\section{Gender}

The Figure 1 depicts the respondents' demographic according to the gender. Of the $n=50$ participants, $n=29$ of respondents in the study representing (58\%) were female while male scored $n=21$ representing (42\%). The study shows that females were more outgoing and willing to participate than man in the area the research was conducted. This research result on gender can be related to Thompson and Conradie (2011:45), who mention that women's willingness to participate in community duties is their instinct as women to protect and secure an acceptable level of socio-economic which will secure the wellbeing of their families.

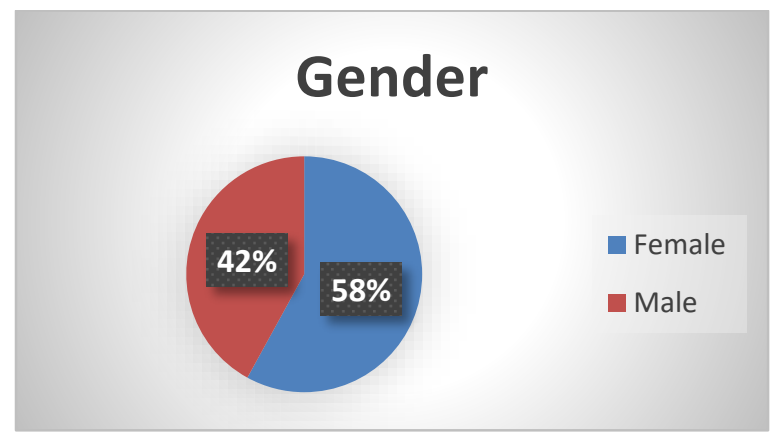

Figure 2: Gender

Source: Authors' own research results/contribution.

\section{Status}

The following Figure 2 indicates the status of the respondents in the research. Of the respondents, the majority of $n=39$ indicating $(78 \%)$ where single while $n=11$ representing $(22 \%)$ were married.

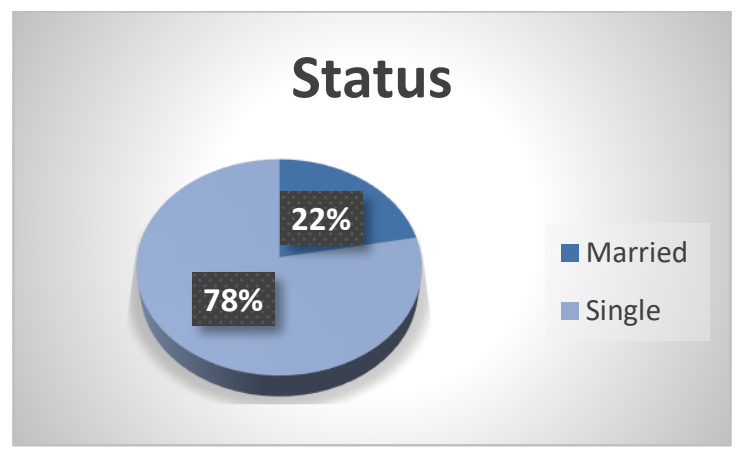

Figure 3: Status

Source: Authors' own research results/contribution.

\section{Participant age}

The questionnaire had a category of age designed to describe a respondent's age. Respondents were asked to choose their respective categories of age. Figure 4 captures how the age was considered and what the responses were in each of the categories. This figure 
shows that the majority of respondents, $n=27$ (54\%), were aged between 20-30 years. The second-highest category with the frequency of $n=13(26 \%)$ were respondents categorized between $30-40$ years old. With a frequency of $n=7,14 \%$ were over 40 years old and $n=3(6 \%)$ were under 20 years old. From the research result, the majority of respondents were young.

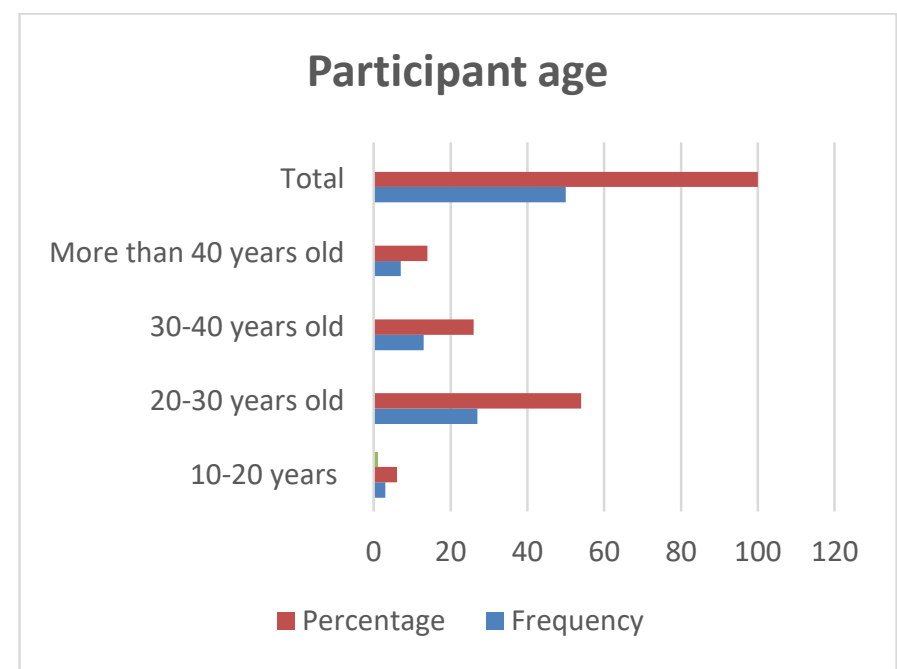

Figure 4: Participant Age

Source: Authors' own research results/contribution.

\section{Sustainable Development affected by social entrepreneurship}

The most common result concerning whether social entrepreneurship was well implemented to reach the sustainable development of the area the research where conducted were "Yes" with an $n=34$ representing (68\%), affirming that social entrepreneurs activities are actually well implemented to develop the community and meet sustainable development. When asked to identify what change or outcome social entrepreneurs have brought on their community, the result was mainly skills, humanity and education around young and old people.

The remaining n=16 representing (32\%) results were "no", they answered that "the results that the procedure used to develop the community require involvement of external and internal stakeholder's initiatives that can be implemented toward improving the lives of people in the communities".

Figure 5 represents Social activities if well implemented to develop the community of the area the research where conducted. 


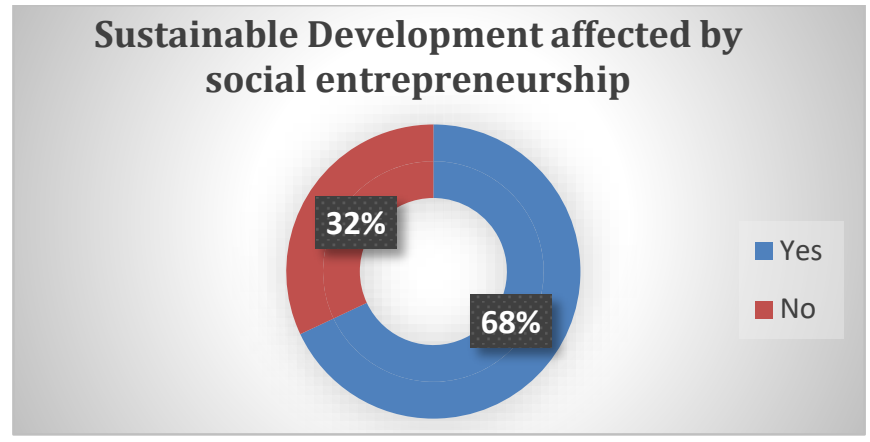

Figure 5: Sustainable Development affected by social entrepreneurship

Source: Authors' own research results/contribution.

Social activities difference in the community

The question was asked to identify the difference that participants brought through their social activities to the community. The result shows important similarities in the answers of the respondents. The difference made by their social activities from the respondents was to reduce poverty by raising an intensive awareness of children to protect them from drugs through their campaigns and sponsorship. The result also shows that another difference was to give people in the community the feeling of working side by side to deal with their problems and improvements together.

\section{Hypothesis I}

The below main hypothesis was formulated.

HO: Social entrepreneurship is contributing to sustainable development in Lebanon

H1: Social entrepreneurship is not contributing to sustainable development in Lebanon

In order to achieve the main hypothesis the below sub hypothesis was formulated:

\section{Hypothesis Testing}

I. Studying whether the "The extent of the impact made for the success of community development "has same effect among the three groups of "Health".

H0: "The extent of the impact made for the success of community development "has same effect among the four groups as of "Health".

H1: "The extent of the impact made for the success of community development "has different effect among the four groups as of "Health".

The below tables were extracted using the SPSS statistics system

Table 1. Descriptive Statistics

\begin{tabular}{|l|r|r|r|r|r|}
\hline & \multicolumn{1}{|c|}{$N$} & \multicolumn{1}{c|}{ Mean } & Std. Deviation & Minimum & Maximum \\
\hline $\begin{array}{l}\text { The extent of the impact made for } \\
\text { the success of community } \\
\begin{array}{l}\text { development } \\
\text { Health }\end{array}\end{array}$ & 50 & 1.62 & .602 & & 1 \\
\hline
\end{tabular}

Source: Authors' own research results/contribution. 
Table 2. Ranks

\begin{tabular}{|l|l|r|r|}
\hline & Health & N & Mean Rank \\
\hline \multirow{2}{*}{$\begin{array}{l}\text { The extent of the impact made for the success of } \\
\text { community development }\end{array}$} & Low & 38 & 25.88 \\
\cline { 2 - 4 } & Medium & 11 & 21.95 \\
\cline { 2 - 4 } & Total & 49 & \\
\hline
\end{tabular}

Table 3. Test Statistics ${ }^{a, b}$

\begin{tabular}{|l|r|}
\hline & \multicolumn{1}{|c|}{$\begin{array}{c}\text { The extent of the impact made for the } \\
\text { success of community development }\end{array}$} \\
\hline Chi-Square & .813 \\
df & 1 \\
Asymp. Sig. & .367 \\
\hline
\end{tabular}

a. Kruskal Wallis Test

b. Grouping Variable: Health

Source: Authors' own research results/contribution.

Kruskal Wallis Test shows that $\lambda^{2}=0.813$ and the P-value $=0.367$ (Asymp. Sig. $>5 \%$ ) means that $\mathrm{H} 0$ holds at 5\% level, hence "The extent of the impact made for the success of community development " has same effect among the four groups of "Health".As mentioned in table 1 that the sample size of $\mathrm{N}=50$, table 2 shows the ranks of the respondent answers between low , medium and high .

II. Studying whether the "The extent of the impact made for the success of community development "has same effect among the four groups as of "Education".

H0: "The extent of the impact made for the success of community development "has same effect among the four groups as of "Education".

H1: "The extent of the impact made for the success of community development "has different effect among the four groups as of "Education".

Table 4. Descriptive Statistics

\begin{tabular}{|l|r|r|r|r||}
\hline & $N$ & Mean & Std. Deviation & Minimum \\
\hline The extent of the impact made for the & 50 & 1.62 & .602 & 1 \\
success of community development & 50 & 1.64 & .631 & 1 \\
Education & 502 & \\
\hline
\end{tabular}

Source: Authors' own research results/contribution.

Table 5. Ranks

\begin{tabular}{|c|c|c|c|}
\hline & Education & $N$ & Mean Rank \\
\hline \multirow{4}{*}{$\begin{array}{l}\text { The extent of the impact made for the success of } \\
\text { community development }\end{array}$} & Low & 22 & 27.30 \\
\hline & Medium & 24 & 25.21 \\
\hline & High & 4 & 17.38 \\
\hline & Total & 50 & \\
\hline
\end{tabular}

Table 6. Test Statistics ${ }^{a, b}$ 


\begin{tabular}{|l|r|}
\hline & \\
& \\
& \multicolumn{2}{|c|}{$\begin{array}{c}\text { The extent of the impact made for the success of } \\
\text { community development }\end{array}$} \\
\hline Chi-Square & \\
$d f$ & \\
Asymp. Sig. & \\
\hline
\end{tabular}

a. Kruskal Wallis Test

b. Grouping Variable: Education

Source: Authors' own research results/contribution

Kruskal Wallis Test shows that $\lambda^{2}=2.008$ and the P-value $=0.366$ (Asymp. Sig. $>5 \%$ ) means that $\mathrm{H} 0$ holds at $5 \%$ level, hence "The extent of the impact made for the success of community development " has same effect among the four groups of "Education".

As mentioned in table 4 that the sample size of $\mathrm{N}=50$, table 5 shows the ranks of the respondent answers between low , medium and high .

III. Studying whether the "The extent of the impact made for the success of community development "has same effect among the four groups as of "Economic".

H0: "The extent of the impact made for the success of community development "has same effect among the four groups as of "Economic".

H1: "The extent of the impact made for the success of community development "has different effect among the four groups as of "Economic".

Table 7. Descriptive Statistics

\begin{tabular}{|l|r|r|r|r|r|}
\hline & $N$ & Mean & Std. Deviation & Minimum & $\begin{array}{c}\text { Maximu } \\
m\end{array}$ \\
\hline $\begin{array}{l}\text { The extent of the impact made for the } \\
\text { success of community development }\end{array}$ & 50 & 1.62 & .602 & 1 & 3 \\
Economic & 50 & 1.66 & .593 & 1 & 3 \\
\hline
\end{tabular}

Source: Authors' own research results/contribution.

Table 8. Test Statistics ${ }^{a, b}$

\begin{tabular}{|l|rr|}
\hline & & \\
& & \\
& \multicolumn{2}{|c|}{ The extent of the impact made for the success of } \\
\hline Chi-Square & \multicolumn{2}{|c|}{ community development } \\
df & & 1.823 \\
Asymp. Sig. & 2 \\
\hline
\end{tabular}

a. Kruskal Wallis Test

b. Grouping Variable: Economic

Source: Authors' own research results/contribution. 
Table 9. Jonckheere-Terpstra Test ${ }^{a}$

\begin{tabular}{|l|r|}
\hline & $\begin{array}{l}\text { The extent of the impact made } \\
\text { for the success of community } \\
\text { development }\end{array}$ \\
\hline Number of Levels in Economic & 3 \\
$N$ & 50 \\
Observed J-T Statistic & 383.500 \\
Mean J-T Statistic & 340.500 \\
Std. Deviation of J-T Statistic & 46.666 \\
Std. J-T Statistic & .921 \\
Asymp. Sig. (2-tailed) & .357 \\
\hline
\end{tabular}

Source: Authors' own research results/contribution.

Kruskal Wallis Test shows that $\lambda^{2}=1.823$ and the P-value $=0.357$ (Asymp. Sig. $>5 \%$ ) means that $\mathrm{H} 0$ holds at $5 \%$ level, hence "The extent of the impact made for the success of community development " has same effect among the four groups of "Economic. As mentioned in table 7 that the sample size of $\mathrm{N}=50$, table 8 shows the ranks of the respondent answers between low , medium and high .

\section{Frequencies}

For education, 22 participants answered Low, 24 Medium and only 4 High. Hence, 92\% of the participants believe that Education has low to Medium Impact.

Table 10. Education

\begin{tabular}{|ll|r|r|r|r|}
\hline & & & & \multicolumn{1}{c|}{$\begin{array}{c}\text { Cumulative } \\
\text { Percent }\end{array}$} \\
\hline Valid & Low & 22 & 43.1 & 44.0 & 44.0 \\
& Medium & 24 & 47.1 & 48.0 & 92.0 \\
& High & 4 & 7.8 & 8.0 & 100.0 \\
& Total & 50 & 98.0 & 100.0 & \\
Missing & System & 1 & 2.0 & & \\
Total & & 51 & 100.0 & & \\
\hline
\end{tabular}

Source: Authors' own research results/contribution.

For Health, 38 participants answered Low, 11 Medium and zero High. Hence, 100\% of the participants believe that health has low to Medium Impact.

Table 11.Health

\begin{tabular}{|l|r|r|r|r|}
\hline & Frequency & Percent & Valid Percent & $\begin{array}{c}\text { Cumulative } \\
\text { Percent }\end{array}$ \\
\hline Valid Low & 38 & 74.5 & 77.6 & 77.6 \\
\hline
\end{tabular}




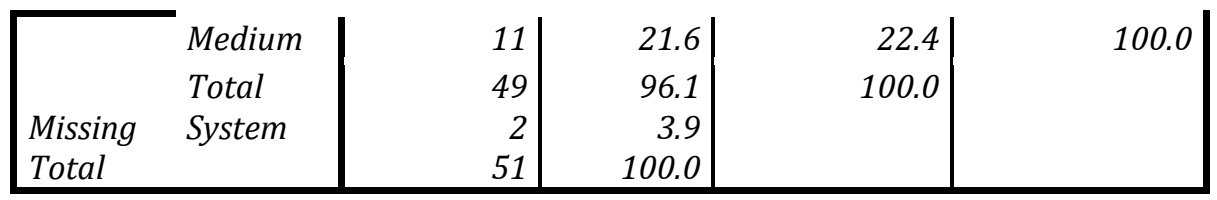

Source: Authors' own research results/contribution.

For Economic, 20 participants answered Low, 27 Medium and 3 High. Hence, 94\% of the participants believe that economic has low to Medium Impact.

Table 11. Economic

\begin{tabular}{|ll|r|r|r|r|}
\hline & & & & Cumulative \\
Frequency & Percent & Valid Percent & Percent \\
\hline Valid & 20 & 39.2 & 40.0 & 40.0 \\
& Medium & 27 & 52.9 & 54.0 & 94.0 \\
& High & 3 & 5.9 & 6.0 & 100.0 \\
& Total & 50 & 98.0 & 100.0 & \\
Missing & System & 1 & 2.0 & & \\
Total & 51 & 100.0 & \\
\hline \multicolumn{6}{|c|}{ Source: Authors'own research results/contribution } \\
\hline
\end{tabular}

For environment, 22 participants answered Low, 25 Medium and 3 High. Hence, $94 \%$ of the participants believe that environment has low to Medium Impact.

Table 12. Environment

\begin{tabular}{|ll|r|r|r|r|}
\hline & Frequency & Percent & $\begin{array}{c}\text { Valid } \\
\text { Percent }\end{array}$ & $\begin{array}{c}\text { Cumulative } \\
\text { Percent }\end{array}$ \\
\hline Valid & Low & 38 & 74.5 & 76.0 & 76.0 \\
& Medium & 12 & 23.5 & 24.0 & 100.0 \\
& Total & 50 & 98.0 & 100.0 & \\
Missing & System & 1 & 2.0 & & \\
Total & & 51 & 100.0 & & \\
\hline
\end{tabular}

Source: Authors' own research results/contribution.

Table 13. The extent of the impact made for the success of community development

\begin{tabular}{|ll|r|r|r|r|}
\hline & & & & Cumulative \\
& & Frequency & Percent & Valid Percent & \multicolumn{1}{|c|}{ Percent } \\
\hline Valid & Low & 22 & 43.1 & 44.0 & 44.0 \\
& Medium & 25 & 49.0 & 50.0 & 94.0 \\
& High & 3 & 5.9 & 6.0 & 100.0 \\
& Total & 50 & 98.0 & 100.0 & \\
Missing & System & 1 & 2.0 & & \\
Total & 51 & 100.0 & & \\
\hline
\end{tabular}

Source: Authors' own research results/contribution

The extent of the impact made for the success of community development 22 participants answered Low, 25 Medium and 3 High. Hence, 94\% of the participants believe that the impact made has low to Medium for the success of community development 


\section{Conclusion}

As a conclusion according to this paper, social entrepreneurs have an essential role to perform in the transformation of the society. Social entrepreneurship indicates advanced and financially maintainable actions directed at social difficulties. Social entrepreneurs perform as the means of change for society, taking advantage of opportunities that is lacked by others for improving the system, discovering new methods and generating enhanced solutions to change the society. However in Lebanon, the social entrepreneurship interest has become greater than before. Support for a social enterprise, mirrored in the willingness to allow, care and encourage entrepreneurship by providing all needed capitals, is a critical issue in the improvement of social entrepreneurship.

Social entrepreneurship has quickly proven itself as a dynamic arena of practice and academic question. So the only method to be sustainable is when individuals become entrepreneurial and are capable to earn profit in their daily processes to be used in accomplishing their social objectives. With the effect of social entrepreneurship on education, health and economic sectors mentioned previously, social entrepreneurship can be a solution. As every research this study has a limitation regarding the sample selected for testing is equal to 50 participants which is considered small, which impeded the ability to generalize the observations. Consequently, the conclusions reached are limited to the analysis of the questionnaire collected.Therefore, it is suggested that this study be embedded to cover a broader population and a more representative sample.

\section{References}

Alvord, S. H., Brown, L. D., \& Letts, C. W. (2004). Social entrepreneurship and societal transformation: An exploratory study. The journal of applied behavioral science, 40(3), 260-282.

Bornstein, D. (2007). How to change the world: Social entrepreneurs and the power of new ideas. Oxford University Press.

Bell, E., Bryman, A., \& Harley, B. (2015). Business research methods. Oxford university press. Bhatt, Ela (1989). Toward Empowerment, World Development Journal, Volume 17, No. 7

Emerson, J., \& Twersky, F. (Eds.). (1996). New social entrepreneurs: The success, challenge and lessons of non-profit enterprise creation. The Homeless Economic Fund, the Roberts Foundation.

Kao, J. J., \& Stevenson, H. H. (1984). Report of the Colloquium on Entrepreneurship. Division of Research, Harvard Business School.

Martin, R. L., \& Osberg, S. (2007). Social entrepreneurship: The case for definition (Vol. 5, No. 2, pp. 28-39). Stanford, CA: Stanford social innovation review.

Stevenson, H. H., \& Jarillo, J. C. (2007). A paradigm of entrepreneurship: Entrepreneurial management. In Entrepreneurship (pp. 155-170). Springer, Berlin, Heidelberg.

Zahra, S. A., Gedajlovic, E., Neubaum, D. O., \& Shulman, J. M. (2009). A typology of social entrepreneurs: Motives, search processes and ethical challenges. Journal of business venturing, 24(5), 519-532.

Schaltegger, S., \& Wagner, M. (2011). Sustainable entrepreneurship and sustainability innovation: categories and interactions. Business strategy and the environment, 20(4), 222-237. 
Sustainable development goals. (2018). Retrieved from www.sdglebanon.com: https://sustainabledevelopment.un.org/memberstates/lebanon

Thompson, L., \& Conradie, I. (2011). From poverty to power? Women's participation in intermediary organisations in site C, Khayelitsha. Africanus, 41(1), 43-56. 